\title{
CAN TAXES ON CARS AND ON GASOLINE MIMIC AN UNAVAILABLE TAX ON EMISSIONS?
}

Don Fullerton Sarah West

Working Paper 7059

http://www.nber.org/papers/w7059

\author{
NATIONAL BUREAU OF ECONOMIC RESEARCH \\ 1050 Massachusetts Avenue \\ Cambridge, MA 02138 \\ March 1999
}

\begin{abstract}
We are grateful for helpful comments from Winston Harrington, Robert Innes, Raymond Robertson, Dan Slesnick, Kenneth Small, Margaret Walls, Pete Wilcoxen, Paul Wilson, and Ann Woverton. In addition, we would like to thank the Public Policy Institute of California (PPIC) for funding this research. This paper is part of NBER's research program in Public Economics. The views expressed in this paper are those of the authors and do not reflect those of the PPIC or the National Bureau of Economic Research.

( 1999 by Don Fullerton and Sarah West. All rights reserved. Short sections of text, not to exceed two paragraphs, may be quoted without explicit permission provided that full credit, including ${ }^{(0)}$ notice, is given to the source.
\end{abstract}


Can Taxes on Cars and on Gasoline Mimic

an Unavailable Tax on Emissions?

Don Fullerton and Sarah West

NBER Working Paper No. 7059

March 1999

JEL No. D62, H23, Q28

\section{ABSTRACT}

A tax on vehicle emissions can efficiently induce all of the cheapest forms of abatement. Consumers could drive less, buy a smaller car with better gas mileage, use cleaner gasoline, and repair pollution control equipment (PCE). However, the technology is not yet available to measure and tax each car's total emissions. We thus investigate alternative instruments. In a simple model with identical consumers, we show conditions under which the same efficiency can be attained by the combination of a tax on gas, a tax on engine size, and a subsidy to PCE. In a model with heterogeneous consumers, the same efficiency can again be obtained, but only if each person's gasoline tax rate can be made to depend on the characteristics of the car. We solve for these firstbest tax rates. Assuming that tax rates must be uniform across consumers, we then characterize second-best tax rates on gasoline and on characteristics.

Don Fullerton

Department of Economics University of Texas at Austin

Austin, TX 78712

and NBER

dfullert@eco.utexas.edu
Sarah West

Department of Economics

University of Texas at Austin

Austin, TX 78712

sewest@maxwell.syr.edu 
Continued growth of cities, increases in vehicle-miles traveled, and Americans' renewed love for large vehicles contribute to increasing externalities from vehicle emissions, including worsened health, diminished visibility, and possible global warming. Technological advances in the measurement of car emissions renew hope that a tax can be levied directly on these emissions (Harrington, et al., 1994). If so, individuals would reduce pollution efficiently (Pigou, 1932). At least for the time being, however, the emissions taxes or permits that work well for stationary sources such as electric generating plants are not considered feasible for mobile sources of pollution. The technology is not available to measure the emissions of each vehicle in a way that is cost-effective and reliable, that is resistant to tampering by the vehicle's owner, and that satisfies legal restrictions against the search of a private vehicle. In this paper, we investigate alternative market incentives for the reduction of car pollution.

We focus on economic incentives because these kinds of policies "tend to be less costly than approaches which regulate the technology of the car or the fuel" (Harrington, et al., 1994: p. 16). ${ }^{1}$ If a true Pigovian tax on vehicle emissions were available, it would reduce pollution by inducing households to drive fewer miles, to buy fuel-efficient cars, to install pollution control equipment $(P C E)$, to purchase cleaner fuel, to avoid cold start-ups, and perhaps to drive less aggressively. ${ }^{2}$ Thus, any efficient alternative policy would need to induce the same behavior. In this paper, we investigate combinations of other policies that would influence people to buy smaller cars, better pollution control equipment, and cleaner fuel with lower volatility or higher levels of oxygenation. Moreover, a true Pigovian tax would automatically account for consumer

\footnotetext{
${ }^{1}$ For an estimate of the cost savings from the use of incentive instruments rather than mandates, see Kling (1994). For a review of such studies, see Bohm and Russell (1985). Many researchers evaluate costs of current air pollution or the costs and benefits of abatement due to new vehicle and fuel technologies (Faiz, et al., 1996; Hall, et al., 1992; Kahn, 1996a; Kazimi, 1997; Krupnick and Portney, 1991; Krupnick and Walls, 1992; Small and Kazimi, 1995). Others focus on the effects of command and control (CAC) policies such as emissions requirements and Corporate Average Fuel Economy (CAFE) standards (Goldberg, 1998; Harrington, 1997; Kahn, 1996b).

${ }^{2}$ Because of cold-start up emissions, Burmich (1989) finds that a 5-mile trip has almost three times the emissions per mile as a 20-mile trip at the same speed. Sierra Research (1994) finds that a car driven aggressively has a carbon monoxide emissions rate that is almost 20 times higher than when driven normally.
} 
heterogeneity. For example, the driver of a dirty car would pay more tax than the driver of a clean car, for the same miles.

Our specific question is whether a combination of taxes on gasoline and on cars can achieve this efficient outcome. It is an example of the general problem in public economics regarding the optimal correction of externalities in the face of heterogeneity.

To determine the form of these efficient policy combinations, we model the household choice of miles, vehicle attributes, pollution control equipment (PCE), fuel cleanliness, and other goods. Initially, we clarify our basic framework using a model of homogeneous consumers. We then allow consumers to differ by income and by two taste parameters, one for miles and the other for vehicle size. We use our model of heterogeneous consumers to find closed-form solutions for a first-best gas tax that depends on the vehicle, and a tax on the vehicle that depends on miles driven. Since these measurements may be too costly, we derive conditions that characterize secondbest optimal uniform tax rates. We then discuss how these optimal uniform tax and subsidy rates may depend on the joint distribution of tastes for miles and engine size. ${ }^{3}$

This paper builds upon a large literature pertaining to vehicle emissions, but it also builds upon a different body of literature pertaining to other types of emissions when a Pigovian tax is not available. Eskeland and Devarajan (1996) show how different combinations of policies can be used to approach the effect of a Pigovian tax. Fullerton (1997) introduces a "two-part instrument" and shows how it can exactly match the effects of a Pigovian tax on industrial emissions, at least in a simple model with homogeneous firms and consumers. As shown in Fullerton and Wolverton (1999), a tax on output is equivalent to a tax on all inputs, including both clean inputs and dirty inputs (emissions). Then this tax is returned as a subsidy to all inputs except emissions. In this way, emissions remain the sole taxed input.

\footnotetext{
${ }^{3}$ Optimal tax results are derived here analytically, using general functional forms. In a later paper, Fullerton and West (1999) assign specific functional forms, use a large sample of households, simulate second-best policies, and compare welfare gains as a percentage of the gain from the ideal-butunavailable Pigovian tax.
} 
The vehicle emission literature also struggles with the special information problems associated with pollution. ${ }^{4}$ For example, Eskeland (1994) builds a simple general equilibrium model with homogeneous consumers and fixed abatement mandates, and he then finds the additional welfare-improving tax on gasoline. Harrington, et al. (1998) consider the cost-effectiveness of a mandated vehicle inspection and maintenance ( $\mathrm{I} / \mathrm{M})$ program compared to an incentive program under conditions of uncertainty. The incentive is a fee that is based on the vehicle's emission rate, assuming miles are not observable. Thus, motorists can reduce their fee by repairing their vehicle, but not by driving less. Sevigny (1998) incorporates the choice of miles with a second-best emissions tax, but this tax requires knowledge of each vehicle's average emissions per mile and the accurate measurement of miles traveled. ${ }^{5}$

Since our paper provides a general equilibrium model with heterogeneous consumers who can choose miles and car characteristics, it is most similar to the existing paper by Innes (1996). He also analyzes first-best and second-best combinations of feasible policy instruments. We state below where some of our results confirm those of Innes, but we also show how some other results differ in ways that can be attributed to assumptions employed in each model. Because of the recent increase in consumers' affinity for large vehicles, we focus on engine size as one important determinant of emissions. ${ }^{6}$ Thus our model differs from Innes in three respects. First,

\footnotetext{
${ }^{4}$ For example, Kohn (1996) shows that any combination of a tax on vehicle emissions and a subsidy to emissions abatement are equivalent. For any such combination to be administered, however, emissions must be measurable. Train, et al. (1997) analyze "feebates," in which rebates are provided to vehicles with higher-than-average fuel efficiency and fees are levied on less efficient vehicles. These feebates are feasible incentives because fuel efficiency can be measured, but they are not perfectly efficient because they do not depend on miles driven.
}

\footnotetext{
${ }^{5}$ All of these schemes are imperfect. Emissions per mile (EPM) cannot be measured perfectly, because it depends on how the car is driven. Miles cannot be measured perfectly, because drivers can roll back the odometer. Harrington et al (1994) discuss remote sensing at a selection of locations as a good approximation, but some drivers may disproportionately miss or intentionally avoid those locations. Our schemes are not perfect either, as they miss some behaviors mentioned above (cold start-ups, aggressive driving).

${ }^{6}$ Current Clean Air Act regulations impose the same restrictions on all cars, so new-vehicle emissions vary by engine size only because of weaker regulations for trucks and sport utility vehicles (SUV). Light trucks and SUVs are "one out of every two family vehicles sold," and will be the "fastest growing source of global warming gases in the United States over the next decade" (Bradsher, 1997,p. A24). In addition, actual subsequent emissions rates may vary by engine size, even within a vehicle class.
} 
we allow consumer heterogeneity in terms of two different taste parameters (for miles and for engine size). Second, we write explicit expressions for miles per gallon (MPG) and emissions per mile ( $E P M)$ that are functions of engine size and other car characteristics. Third, we derive closed-form solutions for first-best tax rates on gasoline, engine size, and PCE.

In a simple model with homogeneous consumers, we find that the effects of a first-best Pigovian tax on emissions can be replicated perfectly by a three-part instrument with tax rates on gasoline, engine size, and $P C E$. In a model with heterogeneity, however, the first best requires that the gasoline tax depend on engine size and that the tax on size depend on miles driven. Such rates may not be feasible, so we solve for conditions that characterize the second-best uniform rate of tax on gasoline (for all vehicles) and on engine size (for any mileage). This model presents policymakers with complicated conditions for setting these second best tax rates, so we then investigate easier approaches. In particular, we investigate the bias from the simple but erroneous assumption that consumers are homogeneous and that all drive the mean number of miles in the mean sized car (using the closed-form expressions for first-best tax rates, evaluated at mean miles and engine size). As it turns out, this bias depends on convexity of $M P G$ and $E P M$ as functions of engine size, and on the correlation in consumer preferences for desired miles and engine size. Preliminary evidence suggests that both $M P G$ and $E P M$ are convex, and that therefore the erroneous assumption of homogeneity would understate the desired second-best uniform tax on gasoline. On the other hand, preliminary evidence suggests that miles and engine size are negatively correlated and that therefore the erroneous assumption of homogeneity would overstate the desired second-best uniform tax on engine size.

\section{Homogeneous Consumers}

In this section, we use a simple model of homogeneous consumers to exposit the basic characteristics of a first-best policy package. This model provides three main insights into the problem of controlling vehicle pollution. First, this model shows a case in which a three-part instrument is equivalent to a Pigovian tax on car emissions. This 
policy package includes taxes on gasoline and "size" and a subsidy to a "clean-car characteristic." Second, if emissions per mile depend on clean-fuel characteristics, a subsidy to such attributes is not necessary as long as the gas tax can depend on the amount of this attribute. Third, consumers may or may not derive utility from the clean-car or clean-fuel characteristic. If not, the government would have to subsidize consumers by 100 percent of the cost of the clean characteristic (such as PCE or fuel additives) in order to influence them to buy any of it. Moreover, because consumers are then indifferent between buying and not buying the clean good, the quantity purchased is indeterminate. These are the reasons that Innes (1996) includes mandates for cleaner fuel in his optimal second-best policy package. ${ }^{\text {. }}$

The homogeneous-consumer model is constructed in the spirit of Baumol and Oates (1988), as extended by Fullerton and Wolverton (1999). For this exposition, we simplify the analysis by assuming that information is perfect, lump-sum taxes are available, and the only market failure is a negative externality from emissions. This is a general equilibrium model, but a simple one where production prices are fixed (and consumer prices vary with tax rates). The economy consists of $n$ identical households, each of which owns one vehicle. Each vehicle is made up of characteristics that affect emissions such as engine size, fuel efficiency, and PCE, and characteristics that do not affect emissions (such as leather seats or a sunroof). Households buy gasoline in order to drive miles, and they choose among grades of fuel-cleanliness.

Households gain utility from driving miles $m$, the "size" of the vehicle $s$, and a composite-commodity, $x$. Broadly interpreted, $s$ represents any vehicle characteristic that gives households utility and that increases emissions per mile. More specifically, we can define $s$ to be a measure of engine size such as cubic inches of displacement (CID). Also, consumers may gain or lose utility from pollution-control equipment, $c$, and per-gallon fuel cleanliness, $f$. Pollution-control equipment includes catalytic converters and other emissions-reducing equipment directly installed on a vehicle. In general, this $c$ should reflect the condition as well as the amount of PCE.

\footnotetext{
${ }^{7}$ We ignore existing mandates in the theoretical model below, but we recognize that these mandates affect the estimated ways in which actual emissions per mile depend on engine size and other car characteristics. Thus, incentive policies may work because they encourage purchase of regulated cars.
} 
Fuel cleanliness is an attribute of gasoline such as volatility or oxygenation. ${ }^{8} \mathrm{We}$ assume that cleaner fuel is more expensive. The composite commodity consists of all vehicle characteristics not related to emissions and all other goods purchased by the consumer. In addition, household utility is affected by aggregate auto emissions, $E$. Thus the household's utility function is: ${ }^{9}$

$$
u=u(m, s, c, f, x, E)
$$

The emissions per mile ( $E P M)$ that a car discharges depends positively on size and negatively on $P C E$ and the clean-fuel characteristic. Thus $\operatorname{EPM}=\operatorname{EPM}(s, c, f)$. Since each of the $n$ households drives $m$ miles, aggregate emissions $E$ can be calculated by $n m E P M(s, c, f)$. Next, fuel efficiency is measured in miles per gallon $(M P G)$ and depends on engine size and the quantity of the clean-car good on the vehicle, ${ }^{10}$ so $M P G=M P G(s, c)$. Cars with larger engines get lower gas mileage, so $M P G_{s} \equiv \partial M P G / \partial s$ is negative. The addition of a clean-car characteristic such as a catalytic converter adds weight to a vehicle, diminishing fuel efficiency, and therefore $M P G_{\mathrm{c}}$ is also likely to be negative. ${ }^{11}$

\footnotetext{
${ }^{8}$ More volatile gasoline leads to more evaporative emissions. The addition of oxygenates to gasoline alters the stoichiometric air/fuel ratio. Provided the carburetor setting is unchanged, this alteration may reduce emissions of carbon monoxide (CO) and hydrocarbons (HC), but can also increase emissions of oxides of nitrogen (NOX). And, if the mixture becomes too lean (high air/fuel), HC emissions can increase due to misfiring (OECD, 1995).

${ }^{9}$ Driver utility may also be affected by the age of the vehicle, and vintage is an important determinant of emissions. For simplicity, in this paper, we ignore vintage and thus the possibility of a subsidy to newness. Adding vintage is straightforward, and it yields a newness subsidy analogous to the size tax below (see Fullerton and West, 1999).

${ }^{10}$ Fuel efficiency may also be a function of the clean-fuel characteristic, $f$. Oxygenated fuel contains methyl tertiary butyl ether (MTBE) or ethanol, each of which have lower energy content per gallon than conventional gasoline. For simplicity, we do not incorporate $f$ into $M P G$. Instead, we provide intuitive explanation of this effect when warranted.

${ }^{11}$ According to Dunleep (1992), the addition of one cylinder decreases fuel efficiency by 3 percent. Also, the equipment mandated in U.S. tier 1 emissions regulations lowers fuel efficiency by 1 percent.
} 
Consumers do not purchase $m$ directly, but through the combination they choose of gasoline $(g)$, size $(s)$, and the clean-car characteristic $(c)$. In other words, the demand for gasoline is a derived demand, where

$$
g=\frac{m}{M P G(s, c)}
$$

Consumers incorporate these relationships when they decide what size car and how much gasoline will maximize their utility in equation (1) above.

Our research strategy is to solve the social planner's problem, then solve the household's problem, and compare. We then find tax rates in the household's optimization problem that induce households to behave in a way that achieves the outcome of the social planner's problem.

\section{A. The Social Planner's Problem}

The social planner maximizes the utility of the representative household, subject to the household's income, $y$, by choosing $m, s, c, f$, and $x$. The social planner recognizes that individuals' choices affect aggregate emissions. In other words, the social planner maximizes utility in equation (1) subject to equation (2) and a resource constraint:

$$
u[m, s, c, f, x, n m E P M(s, c, f)]+\delta\left[y-\left(\frac{p_{g}+p_{f} f}{M P G(s, c)}\right) m-p_{s} s-p_{c} c-x\right]
$$

with respect to $m, s, c, f$, and $x$. The price per gallon of gasoline without any clean characteristic is $p_{g}$, and the price per unit of the clean-fuel characteristic per gallon is $p_{f}$. The total price of a gallon of gasoline is $\left(p_{g}+p_{f} f\right)$, and the private cost of driving a mile is $\left(p_{g}+p_{f}\right) / M P G(s, c)$. The price of $s$ is $p_{s}$, which represents the price of adding an additional cubic inch of displacement to an engine. The price per unit of the cleancar characteristic is $p_{c}$, and the price of $x$ is normalized to one. ${ }^{12}$

This maximization yields first-order conditions in equations (4), shown in Table I. Subscripts on $u, E P M$, and $M P G$ indicate partial derivatives $\left(u_{m}=\partial u / \partial m\right)$, and $\delta$

\footnotetext{
${ }^{12}$ In practice, in order to get constant production prices for $s, c$, and $f$, one could define these variables as deviations from their mean values.
} 


\section{Table I: First-Order Conditions with Homogeneous Consumers}

Equations (4) from the social planner's problem:

$$
\begin{aligned}
& u_{m}+u_{E} n E P M(s, c, f)=\delta\left[\frac{p_{g}+p_{f} f}{M P G(s, c)}\right] \\
& u_{s}+u_{E} n m E P M_{s}=\delta\left[p_{s}+m\left(\frac{-\left(p_{g}+p_{f} f\right) M P G_{s}}{M P G(s, c)^{2}}\right)\right] \\
& u_{c}+u_{E} n m E P M_{c}=\delta\left[p_{c}+m\left(\frac{-\left(p_{g}+p_{f} f\right) M P G_{c}}{M P G(s, c)^{2}}\right)\right] \\
& u_{f}+u_{E} n m E P M_{f}=\delta\left[\frac{p_{f} m}{M P G(s, c)}\right] \\
& u_{x}=\delta
\end{aligned}
$$

Equations (6) from the household problem:

$$
\begin{aligned}
& u_{m}=\lambda\left[\left(\frac{p_{g}+t_{g}+\left(p_{f}+t_{f}\right) f}{M P G(s, c)}\right)+t_{e} \operatorname{EPM(s,c,f)]}\right. \\
& u_{s}=\lambda\left[p_{s}+t_{s}+m\left(\frac{-\left(p_{g}+t_{g}+\left(p_{f}+t_{f}\right) f\right) M P G_{s}}{M P G(s, c)^{2}}\right)+t_{e} E P M_{s} m\right] \\
& u_{c}=\lambda\left[p_{c}+t_{c}+m\left(\frac{-\left(p_{g}+t_{g}+\left(p_{f}+t_{f}\right) f\right) M P G_{c}}{M P G(s, c)^{2}}\right)+t_{e} E P M_{c} m\right] \\
& u_{f}=\lambda\left[\frac{\left(p_{f}+t_{f}\right) m}{M P G(s, c)}+t_{e} E P M_{f} m\right] \\
& u_{x}=\lambda\left[1+t_{x}\right]
\end{aligned}
$$


is the marginal social value of income. The quantity in brackets in (4a) is the total implicit price of a mile, while the quantity in brackets in (4b) is the overall cost per unit of size, including the extra amount that must be paid for miles due to the lower $M P G$ caused by the incremental unit of $s$. Similarly, the quantity in brackets in (4c) is the overall cost of $P C E$, including the extra amount that must be paid for miles due to the lower MPG. In (4d), the term in brackets is the overall cost per unit of the clean-fuel characteristic.

These first-order conditions say that the marginal social gain from driving another mile or from an additional unit of $s, c, f$ or $x$, is equal to the marginal social cost of each respective good. The presence of the $u_{E}$ term on the left-hand sides of $(4 \mathrm{a}-4 \mathrm{~d})$ reflects the effect on utility of the increment to aggregate emissions from driving an additional mile, increasing vehicle size, adding $P C E$, or buying cleaner gasoline.

\section{B. The Household Problem}

In contrast to the social planner, a household does not recognize that its own choices affect aggregate emissions. However, it may face taxes or subsidies on its consumption of $s, c, f, x$, and $g$. If it were available, a tax on emissions would enter the budget constraint. The household optimization problem is to choose $m, s, c, f$, and $x$ to maximize:

$$
\begin{gathered}
u(m, s, c, f, x, E) \\
+\lambda\left[y-\left(\frac{\left(p_{g}+t_{g}+\left(p_{f}+t_{f}\right) f\right)}{M P G(s, c)}\right) m-\left(p_{s}+t_{s}\right) s-\left(p_{c}+t_{c}\right) c-\left(1+t_{x}\right) x-t_{e} \operatorname{EPM}(s, c, f) m\right]
\end{gathered}
$$

In the budget constraint, $t_{g}$ is the tax per gallon of gas, $t_{f}$ is the tax per unit of cleanfuel characteristic, $t_{s}$ is the tax per unit of size, $t_{c}$ is the tax per unit of $P C E, t_{x}$ is the tax per unit of $x$, and $t_{e}$ is the tax per unit of emissions.

The first-order conditions for this problem are equations (6), also shown in Table I. Emissions can be made to enter the consumer problem implicitly through the 
pollution $\operatorname{tax} t_{e}$. The price per mile would then include the emissions tax per mile. Similarly, the implicit prices of $s, c$, and $f$ include the emissions tax associated with the change in emissions.

\section{Solutions}

\section{The Pigovian Tax}

The tax on emissions, $t_{e}$, provides the basic efficient policy against which alternatives can be compared. Suppose all other tax rates are set to zero $\left(t_{g}=t_{f}=t_{s}=\right.$ $\left.t_{c}=t_{x}=0\right)$. In this case, (4e) and (6e) imply $\lambda=\delta$. To equate the first order conditions for miles, (4a) and (6a), replace $\lambda=\delta$ into (4a) and subtract it from (6a) to obtain:

$$
t_{e}=\frac{-u_{E} n}{\lambda} \equiv M E D
$$

We define the right-hand side as "marginal environmental damages" (MED) per unit of emissions. It is the sum of all $n$ households' disutilities from emissions, $u_{E}$, translated into money terms when divided by the marginal utility of income. This is the usual Pigovian tax, and it is greater than zero so long as $u_{E}<0$. Using this value of $t_{e}$, and $\lambda=\delta$, then the first order condition (4b) matches $(6 \mathrm{~b}),(4 \mathrm{c})$ matches $(6 \mathrm{c})$, and (4d) matches $(6 \mathrm{~d})$.

Thus the Pigovian tax on emissions by itself induces households to make all the optimal choices. Because of the tax on emissions, consumers will drive fewer miles, buy smaller cars, buy cleaner fuel, and install more pollution control equipment (or opt for a vehicle model that is already equipped with better pollution control equipment).

\section{Taxes on Gasoline and Size with a Subsidy to $P C E$}

If the measurement of emissions were difficult or impossible, so that $t_{e}=0$, we can find a different policy combination that attains the exact same efficient outcome. This policy is a three-part instrument that begins with a tax schedule for gasoline and is complemented by a tax on size and a subsidy to $P C E$. For ease of exposition, we solve for a subsidy on $f$ and show how it can be incorporated into the gasoline tax. To solve for the policy parameters, assume for the moment that $c$ and $f$ do enter household 
utility $\left(u_{c} \neq 0\right.$ and $u_{f} \neq 0$ ). Then, set $t_{x}=t_{e}=0$. Thus $\lambda$ still equals $\delta$, and we have equality between (4e) and (6e). Using $\lambda=\delta$, we can solve for the subsidy on the clean-fuel characteristic by equating (4d) and (6d) to get:

$$
t_{f}=\frac{-u_{E} n}{\lambda} E P M_{f} M P G(s, c)
$$

This tax is negative (a subsidy) as long as emissions per mile decrease with an incremental unit of clean-fuel characteristic. It equals the value of the emissions reduction due to an additional unit of cleanliness per gallon, calculated as the damage per unit of emissions $(M E D)$ times the change in emissions per mile $\left(E P M_{f}\right)$ times miles per gallon $(M P G){ }^{13}$

To solve for the tax on gasoline, plug $\lambda=\delta$ into (4a) and the clean-fuel subsidy (8) into (6a). Then subtract (6a) from (4a) to obtain:

$$
t_{g}=\frac{-u_{E} n}{\lambda} \operatorname{EPM}(s, c, f) M P G(s, c)+\frac{u_{E} n}{\lambda} E P M_{f} f M P G(s, c)
$$

This tax on gasoline has two components. The first term is positive and represents the additional damage caused by an increase of one gallon of gasoline. It is the damage per unit emission $(M E D)$ times emissions per mile (EPM) times miles per gallon (MPG). The second term is also positive. The dollar amount of this second term exactly matches the dollar amount of the subsidy $f t_{f}$ in equation (8), but we cannot just cancel these terms and use only the first term in (9). In effect, a "deposit" is collected in the gas tax, assuming a fixed "baseline" level of $f$, and then a "refund" or subsidy $t_{f}$ encourages the individual to choose more fuel cleanliness $f$. Still, however, the subsidy $t_{f}$ is paid at the same time that $t_{g}$ is collected, so the net result is a schedule that we will call one instrument: a gas tax that depends on the cleanliness of that gas.

To obtain the tax on size, plug $\lambda=\delta$ into (4b) and the clean-fuel subsidy (8) and the gas tax (9) into (6b). Then subtract (6b) from (4b) to obtain:

\footnotetext{
${ }^{13}$ If the clean-fuel characteristic negatively affects $M P G$, the clean-fuel subsidy in (8) would include a positive second term, and the gas tax (below) would include an offsetting term (to leave only the direct effect on emissions).
} 


$$
t_{s}=\frac{-u_{E} n}{\lambda} m\left[E P M_{s}+\operatorname{EPM}(s, c, f) \frac{M P G_{s}}{M P G(s, c)}\right]
$$

Like the gas tax, the size tax has two components. The first term is $-u_{E} n / \lambda$ (that is, $M E D)$ times the change in emissions per mile from a change in size $\left(E P M_{s}\right)$, times miles $(m)$. This gives the direct damage caused by an increase of one unit of size. This term is positive as long as emissions affect utility negatively $\left(u_{E}<0\right)$ and size affects emissions positively $\left(E P M_{s}>0\right)$. The second term is an indirect effect from an additional unit of size through its effect on fuel efficiency. ${ }^{14}$ As long as $M P G_{s}<0$, this term is negative and is thus a rebate. Specifically, it is a rebate of part of the gas tax in (9). Because an additional unit of size decreases fuel efficiency, the household knows that an increase in the size of its vehicle's engine will cost additional gas tax. Thus part of the external cost of size is already internalized by the gas tax. After this rebate, only the cost of size that is separate from its effect on $M P G$ remains taxed. Conceptually, this rebate is the same as that which appears in Innes' second-best vehicle tax, where that tax approximately equals the "predicted social costs of emissions, less the portion of these costs that are internalized by the gasoline tax" (Innes, 1996: p. 212).

Because the two components of the size tax are opposite in sign, this theory does not predict the sign of $t_{s}$. Since the right-hand term before the brackets is positive, the sign of $t_{s}$ is determined by the sign within the brackets. Thus the size tax is positive whenever

$$
\frac{E P M_{s}}{E P M(s, c, f)}>\frac{-M P G_{s}}{M P G(s, c)}
$$

These two terms are proportional effects of size on emissions per mile (EPM) and on miles per gallon (MPG). When an additional unit of size brings about a larger percentage change in emissions per mile than in fuel efficiency, the size tax is positive. If emissions rise at the same rate that fuel efficiency deteriorates, then the size tax is zero. If fuel efficiency deteriorates proportionally more than emissions increase, then size is subsidized! In this last case, the gasoline tax more than completely internalizes

\footnotetext{
${ }^{14}$ Both of these terms contain $m$, the "baseline" number of miles. This $m$ is not the individual's own choice of miles, or else the individual's first order condition (8a) would include the derivative of $t_{s}$ with respect to $m$.
} 
the impact of size on emissions. Empirical exploration of the relative effects in (11) will uncover the sign of the size tax. ${ }^{15}$

To solve for the tax on $P C E$, we follow similar procedures to obtain:

$$
t_{c}=\frac{-u_{E} n}{\lambda} E P M_{c} m+\frac{-u_{E} n}{\lambda} \operatorname{EPM}(s, c, f) m \frac{M P G_{c}}{M P G(s, c)}
$$

The tax on $P C E$ is perfectly analogous to the size tax. The first term is negative to reflect the effect on damages of an added unit of $P C E$. The second term is a rebate due to the effect that $P C E$ has on fuel efficiency (already internalized by the gas tax). Since the second term is also negative, the sign of the clean-car tax is always negative. That is, $t_{c}$ is necessarily a subsidy. ${ }^{16}$

All of these tax rates together induce households to make socially optimal tradeoffs at the margin, so they are valid only for internal solutions. A more complete analysis is required to deal with corner solutions. ${ }^{17}$ If households dislike pollution control equipment enough $\left(u_{c}<<0\right)$, then the subsidy in (12) may not induce them to buy any of it. In this extreme case, the corner solution with $c=0$ is indeed part of the social optimum, even though the marginal conditions (6) are not satisfied. If households care nothing about this equipment, however, then a different problem arises. To see this, note that when $u_{c}=0$, the right-hand side of first order condition (6c) must equal zero at the optimum. By assumption, for this analysis, the emissions tax is set equal to zero. Therefore, to induce consumers to buy any pollution equipment, the subsidy to $P C E\left(t_{c}\right)$ must be equal to the entire private cost of $P C E$, including both the direct cost of equipment, $p_{c}$, and the extra gasoline costs incurred due to the negative

\footnotetext{
${ }^{15}$ Also, note that the size tax in (10) depends on the number of miles driven. Of course, in this model with homogeneous consumers, all households drive the same type of vehicle the same number of miles per year, and the size tax is the same for everyone. When we introduce heterogeneity in Section II, the first-best solution requires that each household pay a size tax that reflects its own choice of miles.

${ }^{16}$ If $c$ measures the amount of $P C E$ installed, this subsidy could be paid upon purchase of the vehicle. More generally, if $c$ reflects the condition of the equipment as well as the amount, then this subsidy could reward testing, maintenance, and repair of $P C E$.

${ }^{17}$ We derived Kuhn-Tucker conditions from a model with non-negativity constraints on the purchase of clean-car and clean-fuel characteristics. The results of that model include equations (9), (10) and (12) for internal solutions and an inequality to characterize each corner solution. The additional intuition is minimal, however, so we just outline these results in the text.
} 
effect that $P C E$ has on fuel efficiency. With a 100 percent subsidy, however, the choice of $c$ is indeterminate. Thus, if $\boldsymbol{u}_{c}=0$, then incentives do not work. The optimal PCE can only be achieved by a mandate (as in Innes, 1996).

The same analysis applies to the clean-fuel characteristic. When $u_{f}=0$, the right-hand side of (6d) must equal zero at the optimum. For households to choose cleaner gas, the subsidy must equal the entire cost of the attribute, $p_{f}$.

Individuals may or may not gain utility from driving cleaner cars and using cleaner fuel. People may like using the latest technologies, or feel peer pressure do so. On the other hand, pollution control equipment may negatively affect performance by increasing vehicle weight and decreasing acceleration. In addition, if cleaner fuel can be found only in a limited number of locations, the inconvenience costs of refueling could be high.

For these reasons, we think that $u_{c}$ and $u_{f}$ are unlikely to be exactly zero. In fact, these marginal utilities are likely to fall with the amount of $c$ or $f$. Even if $u_{c}$ is negative, a big enough subsidy can induce the household to buy more of this good, until $u_{c}$ on the left-hand side of (6c) falls to the level of the (negative) private marginal cost on the right-hand side of $(6 \mathrm{c})$.

The optimality of these results also depends on our assumptions about the available abatement technologies. Since emissions depend on $\operatorname{EPM}(s, c, f)$, the threepart instrument $\left(t_{g}, t_{s}, t_{c}\right)$ attains the same first-best equilibrium as that reached by the Pigovian tax. Despite the fact that emissions are never measured, the three-part policy can attain 100 percent of the improvement in social welfare achieved by the Pigovian $\operatorname{tax}$.

\section{Heterogeneous Consumers}

The tax rates derived in the previous section are uniform across all consumers. In this section, we introduce heterogeneity to see if and when the optimal tax rates need to differ among consumers. If the emissions tax $t_{e}$ were available, we confirm that a 
single $t_{e}=M E D$ would achieve the first-best social optimum (FBSO). If not, then individual-specific tax rates on other goods can still achieve the FBSO. If policy is unable to apply individual-specific tax rates, then it cannot achieve the FBSO. We then characterize the second-best uniform tax rates that best approximate the unavailable tax on emissions.

In his model of heterogeneous consumers, Innes (1996) allows households to differ in terms of income and one taste parameter. In our model, we wish to allow households to differ in terms of income and two taste parameters. We use the parameter $\alpha$ to represent the household's preference for miles, and we use the parameter $\beta$ to represent the preference for size of the car. Together with income, these parameters are jointly distributed according to the distribution function $h(\alpha, \beta, y)$ with positive support on $[\underline{\alpha}, \bar{\alpha}] \times[\underline{\beta}, \bar{\beta}] \times[\underline{y}, \bar{y}]$. The integral of this distribution over $\alpha, \beta$, and $y$ is the population, $n$. In a CES or Cobb-Douglas specification of utility, for example, $\alpha$ could be the weight on miles, $\beta$ would be the weight on size, and $(1-\alpha-\beta)$ would be the weight on $x$. Our analysis is not limited to these special cases, however, and it is not limited by any particular relationship between $\alpha$ and $\beta$. Those who live far from their place of work have a high demand for miles $(\alpha)$, but they may prefer either a small car (for better gas mileage) or a large car (for comfort and safety). We show the importance of the correlation between $\alpha$ and $\beta$.

To focus on the issue of heterogeneity, we now ignore the clean-car and cleanfuel characteristics. Thus fuel efficiency and emissions per mile depend only on size, and each household generates $m E P M(s)$ units of emissions. Aggregate pollution is thus

$$
E=\iint_{\alpha} \int_{y} m E P M(s) h(\alpha, \beta, y) \partial \alpha \partial \beta \partial y
$$

where choices of $m$ and $s$ are individual-specific. A household's utility function is

$$
U=u[m, s, x ; \alpha, \beta, y]-\mu E
$$

where $\mu$ is the household's change in welfare from an additional unit of pollution $(\partial U / \partial E)$. While we allow $\alpha$ and $\beta$ to differ among households, in order to analyze 
different choices and abatement costs, we are not concerned with differential benefits from environmental protection. We thus assume $\mu$ is the same for all consumers.

\section{A. The Social Planner's Problem}

The social planner must maximize a measure of social welfare such as a weighted sum of $n$ households' utilities. To set up this problem, we must specify weights. For present purposes, we want weights that meet three criteria. First, we want to abstract from the welfare effects of any pure redistribution and focus instead on comparing the efficiency of various policies. Therefore, we choose weights so that a dollar given to any household has the same effect on social welfare. To achieve this condition, we divide each household's utility by its own marginal utility of income $(\lambda){ }^{18}$ Second, when $t_{e}$ is available, we want the maximization of our social welfare function to yield the solution of Pigou (1932). Since this solution is based on marginal conditions (such as marginal environmental damages) at the optimum, we use the values for $\lambda$ that occur at the first-best social optimum $(\lambda *)$. Third, we want to be able to compare policies using the same welfare weights. When first-best instruments are not available, we want to be able to find second-best uniform tax rates that maximize the same social welfare function. Therefore we use prices at the Pigovian equilibrium to evaluate $\lambda^{*}$, and we use those $\lambda^{*}$ to get the weights $\left(1 / \lambda^{*}\right)$ for all subsequent evaluations of other policies. The result is a money-metric measure of social welfare.

The social planner's problem is to maximize this welfare function subject to a resource constraint (the integral over all individual budget constraints):

$$
\begin{gathered}
\iint_{\alpha} \int_{y}\left[\frac{u[m, s, x]}{\lambda^{*}}-\mu \iint_{\alpha} \int_{\beta}[m E P M(s)] h(\alpha, \beta, y) \partial \alpha \partial \beta \partial y\right] h(\alpha, \beta, y) \partial \alpha \partial \beta \partial y \\
+\delta\left[\iint_{\alpha} \int_{y}\left[y-\frac{p_{g}}{M P G(s)} m-p_{s} s-x\right] h(\alpha, \beta, y) \partial \alpha \partial \beta \partial y\right]
\end{gathered}
$$

\footnotetext{
${ }^{18}$ To avoid redistributions in the tax rate problem below, we assume that all tax revenues are returned in lump-sum fashion to the same consumer.
} 
with respect to each consumer's $m, s$, and $x$ (given their individual $\alpha, \beta$ and $y$ ). The multiplier on the resource constraint is $\delta$, the marginal social value of income. To maximize (15), we can ignore the outer integral to obtain the individual marginal conditions and then incorporate the impact an individual's choice of miles and size has on emissions by differentiating the aggregate emissions term with respect to the individual's $m$ and $s$.

The resulting first-order conditions for household $i$ are equations (16), shown in the top of Table II. The first term in each equation represents the individual's money value of marginal utility from each good. The second term in (16a) represents the external cost of an additional mile driven by individual $i$. Similarly, the second term in (16b) represents the external cost of an additional unit of size purchased by individual $i$. The first-order conditions (16) say that the money-metric social marginal utility of each good equals the social marginal cost of that good. Also, looking at (16c), note that the left-hand side equals individual $i$ 's change in utility from an additional unit of $x$, divided by the marginal utility of income. In other words, it is the dollar value of another unit of $x$ (the price of $x$ ). Since the price of $x$ equals one, (16c) says that the social marginal utility of income, $\delta$, also equals one.

\section{B. The Household Problem}

In contrast to the social planner, a household does not recognize that its own emissions add to aggregate emissions. The household problem is to maximize:

$$
u_{i}\left(m_{i}, s_{i}, x_{i}, E\right)+\lambda_{i}\left[y_{i}-\left(\frac{\left(p_{g}+t_{g}\right)}{M P G\left(s_{i}\right)}\right) m_{i}-\left(p_{s}+t_{s}\right) s_{i}-\left(1+t_{x}\right) x_{i}-t_{e} E P M\left(s_{i}\right) m_{i}\right]
$$

with respect to $m_{i}, s_{i}$, and $x_{i}$. The first-order conditions are shown in equations (18) of Table II. These equations are heterogeneous counterparts to the first-order conditions (6) of Table I, but without the clean-car and clean-fuel characteristics. In addition, each consumer has a separate set of optimality conditions.

C. Solutions

1. The Pigovian Tax 
Table II: First-Order Conditions with Heterogeneous Consumers

Equations (16) from the social planner's problem:

$$
\begin{aligned}
& \frac{\left(\frac{\partial u_{i}}{\partial m_{i}}\right)}{\lambda_{i}^{*}}-n \mu E P M\left(s_{i}\right)=\delta\left[\frac{p_{g}}{M P G\left(s_{i}\right)}\right] \\
& \frac{\left(\frac{\partial u_{i}}{\partial s_{i}}\right)}{\lambda_{i}^{*}}-n \mu m_{i} E P M_{s i}=\delta\left[p_{s}+m_{i}\left(\frac{-p_{g} M P G_{s i}}{M P G\left(s_{i}\right)^{2}}\right)\right] \\
& \frac{\left(\frac{\partial u_{i}}{\partial x_{i}}\right)}{\lambda_{i}^{*}}=\delta
\end{aligned}
$$

Equations (18) from the household problem:

$$
\begin{aligned}
& \frac{\partial u_{i}}{\partial m_{i}}=\lambda_{i}^{*}\left[\left(\frac{p_{g}+t_{g}}{M P G\left(s_{i}\right)}\right)+t_{e} \operatorname{EPM}\left(s_{i}\right)\right] \\
& \frac{\partial u_{i}}{\partial s_{i}}=\lambda_{i}^{*}\left[p_{s}+t_{s}+m_{i}\left(\frac{-\left(p_{g}+t_{g}\right) M P G_{s i}}{M P G\left(s_{i}\right)^{2}}\right)+t_{e} E P M_{s i} m_{i}\right] \\
& \frac{\partial u_{i}}{\partial x_{i}}=\lambda_{i}^{*}\left[1+t_{x}\right]
\end{aligned}
$$


To solve for a Pigovian tax, set all taxes except $t_{e}$ equal to zero $\left(t_{s}=t_{g}=t_{x}=0\right)$. Then, using $\delta=1,(16 \mathrm{c})$ and (18c) match each other. Also using $\delta=1$, set (16a) and (18a) equal to each other. The household-specific variables drop out, leaving:

$$
t_{e}=\frac{n \mu}{\delta} \equiv M E D
$$

Using $\delta=1$ and this value of $t_{e}$, then first-order conditions for size (16b) and (18b), also match each other.

Thus, given the weights we have chosen, a uniform Pigovian tax on emissions by itself induces all households, no matter their tastes for miles and size, to drive the optimal number of miles in the right sized cars. Of course, policy makers do not necessarily weight households so that income to one is the same as income given to another. They may want instead to incorporate explicit distributional concerns into environmental taxes. In this paper, however, we are not concerned with issues of distribution. We weight households simply in a way that implies that the maximization of social welfare yields the standard Pigovian formula in (19). This first-best uniform Pigovian tax can be used as a benchmark to identify other first-best policy instruments, and more importantly, against which to evaluate other second-best instruments.

\section{First-best Taxes on Gasoline and Size}

As in the representative-agent model, when a Pigovian tax is not possible $\left(t_{e}=\right.$ 0 ), we can derive another first-best set of instruments. Using the solution technique explained in Section I.C, we obtain the heterogeneous counterpart of the gasoline tax:

$$
t_{g i}=n \mu E P M\left(s_{i}\right) M P G\left(s_{i}\right)
$$

The subscript $i$ on size indicates that the first-best tax on gasoline would have to differ across consumers according to their chosen size $\left(s_{i}\right)$. In order for the FBSO to be attained, the tax on gasoline must differ according to characteristics of the vehicle at the pump. Such a gas tax would be costly to administer. ${ }^{19}$

19 "For example, a tamper-resistant computer code would likely be required on each automobile; similarly, gasoline pumps would have to be equipped to automatically tack the appropriate tax onto any 
With heterogeneous consumers, the size tax is also household-specific: ${ }^{20}$

$$
t_{s i}=n \mu E P M_{s i} m_{i}+\frac{n \mu E P M\left(s_{i}\right) M P G_{s i} m_{i}}{M P G\left(s_{i}\right)}
$$

To implement this tax on a car of size $s_{i}$, its miles would have to be known. If the size tax were assessed when the vehicle is purchased, then some measure of the discounted total expected miles for the life of the vehicle would be necessary. Since conditions change, however, the one time size tax would not provide the right subsequent incentives (e.g. retirement). If the size tax were assessed yearly, then annual odometer readings would be necessary. This would provide incentive for individuals to roll back their odometers. ${ }^{21}$

These results can be reconciled with those of Innes (1996). He does not solve for first-best tax rates on gasoline or car characteristics that would replicate the effects of an emissions tax, but he finds that the outcome would include a fuel-content standard, an auto-specific fuel tax, and no regulation of the automobile (p. 226). We derive the auto-specific fuel tax (in 20), but we also find a mileage-specific auto tax (in 21). This difference in results can be attributed directly to differences between the models. The consumer's optimization problem in (17) writes $M P G$ and $E P M$ explicitly as functions of $s_{i}$, but it treats tax rates as parameters that are fixed to the consumer. Yet (20) says that the optimal $t_{g i}$ is $n \mu E P M\left(s_{i}\right) M P G\left(s_{i}\right)$, a function of $s_{i}$. If we plug that $t_{g i}$ function into (17) before we differentiate with respect to $s_{i}$, then additional terms in the first order condition (18b) would involve derivatives $E P M_{s i}$ and $M P G_{s i}$, just like in (21). The tax on size in (21) would then be unnecessary (Innes, 1996). In other words, results depend on what consumers are assumed to know. If

gasoline that is dispensed to a particular automobile. Moreover, since a simple siphoning of gas will permit consumers to bypass taxes on high-emission vehicles, the scope for abuse, particularly among those high-emitting consumers who are arguably the most important targets of the tax, would be tremendous" (Innes, 1996: p. 226).

${ }^{20}$ Again, the FBSO requires that government know $m_{i}$, in order to set the baseline $m_{i}$ in (21), but that the individual face a fixed $t_{s i}$ that does not depend on individual choice of $m$ (the individual optimization of (17) does not take a derivative of $t_{s}$ with respect to $\mathrm{m}$ ).

21 "Even if only a small proportion of consumers cheat in this way, those who cheat are likely to be those who drive the most, who therefore have the greatest incentive to cheat and who are arguably the most important targets of mileage taxation" (Innes, 1996: p. 226-227). 
individuals know that their individualized gas tax rate will depend on their own choice of engine size, then that gas tax alone can induce the optimal size. Preliminary regression results indicate that the effect of size on $E P M$ may be important. We find that emissions per mile are a U-shaped function of engine size. ${ }^{22}$

Successful implementation of these first-best policies seems unlikely. Therefore, we next assume that policy is limited. If the gas tax cannot be made to depend on vehicle type, then a separate tax on size becomes important. If both the size tax and the gas tax are constrained to be uniform across consumers, and therefore fixed to each consumer, then how should these rates be set? Since the tax rates in (20) and (21) depend on $s$ and $m$, one possibility is that the size and gas tax could be calculated from (20) and (21) using the mean size and miles. How well these uniform tax rates would perform depends on the technological relationships $E P M(s)$ and $M P G(s)$ and the relationship in preferences between size and miles. In the next section, we find conditions that characterize second-best (uniform) tax rates. Then, we discuss how these rates might compare with those from (20) and (21) using mean size and miles.

\section{Second-Best Taxes on Gasoline and Size}

To find the second-best tax rates, we must find the single (uniform) gas tax rate and single size tax rate that maximize social welfare, taking as given households' demand behavior for miles, size, and the composite commodity. Assuming producer prices are fixed, this is equivalent to maximizing this weighted sum of indirect utilities:

\footnotetext{
${ }^{22}$ Because an extensive literature search did not yield satisfactory estimates of the effect of engine size on emissions per mile, we use data from the California Air Resources Board (CARB) to obtain our own estimates. The CARB tested the CO, HC, and NOX emissions of 342 gasoline-powered passenger cars, light-duty trucks and medium duty vehicles of model years 1962 through 1995 (CARB, 1997). Emissions per mile of the three pollutants appear to first decrease in CID, then increase, in convex U-shapes. This $\log -\log$ fitted regression for $\mathrm{CO}$ is typical (standard errors in parentheses):

$$
\begin{aligned}
& \ln \mathrm{CO}=34.24-13.28 \ln \mathrm{CID}+1.36 \operatorname{lnCID}^{2} \quad \mathrm{R}^{2}=.14, \mathrm{n}=342 \\
& \text { (8.89) (3.43) (.33) }
\end{aligned}
$$

Regressions that include dummy variables for light trucks and medium-duty vehicles differ little from this one; coefficients on the dummy variables are not statistically significant. 


$$
\iint_{\alpha} \int_{y}\left[\frac{V\left(t_{s}, t_{z}, t_{x} ; y, \alpha, \beta\right)}{\lambda^{*}}-\mu E\right] h(\alpha, \beta, y) \partial \alpha \partial \beta \partial y
$$

with respect to $t_{s}$ and $t_{g}$. As a normalization, the $\operatorname{tax}$ on $x$ can be set to zero, as in the first-best scenario. ${ }^{23}$ Using Roy's Identity, this maximization results in the first order conditions:

$$
\begin{aligned}
& \iint_{\alpha} \int_{y}\left[\frac{-\lambda s}{\lambda^{*}}-\mu \iint_{\alpha} \int_{y}\left[A\left(t_{s}\right)\right] h(\alpha, \beta, y) \partial \alpha \partial \beta \partial y\right] h(\alpha, \beta, y) \partial \alpha \partial \beta \partial y=0 \\
& \iint_{\alpha} \int_{y}\left[\frac{-\lambda g}{\lambda^{*}}-\mu \iint_{\alpha} \int_{y}\left[A\left(t_{g}\right)\right] h(\alpha, \beta, y) \partial \alpha \partial \beta \partial y\right] h(\alpha, \beta, y) \partial \alpha \partial \beta \partial y=0
\end{aligned}
$$

where, (for $j=s, g)$ :

$$
A\left(t_{j}\right) \equiv g M P G(s) E P M_{s} \frac{\partial s}{\partial t_{j}}+g E P M(s) M P G_{s} \frac{\partial s}{\partial t_{j}}+E P M(s) M P G(s) \frac{\partial g}{\partial t_{j}}
$$

The chosen quantities $(s, g$, and $x$ ) as well as the marginal utility of income $(\lambda)$ are functions of $\alpha$ and $\beta$. In (23a), the first term in the integral $\left(-\lambda s / \lambda^{*}\right)$ represents the change in welfare from a change in the size tax, holding aggregate emissions constant. The second term, involving $A\left(t_{s}\right)$, is the change in utility due to the effect that a size tax has on aggregate emissions. ${ }^{24}$ Similarly, the first term in (23b) is the change in welfare from a change in the gas tax, holding aggregate emissions constant. The second term incorporates the change in welfare from the effect that the gas tax has on aggregate emissions.

Thus the tax rates on size and gasoline should each be set so that the aggregate marginal gain in private welfare equals the aggregate loss from the effect on emissions. As shown in the $A\left(t_{j}\right)$ term of each first order condition, the extent to which emissions are reduced depends on the degree of responsiveness of miles and size to taxes on size and gasoline. Thus second-best optimal (SBO) tax rates on size and gasoline depend on

\footnotetext{
${ }^{23}$ Income, $y$, is exogenous, so a (lump-sum) tax on income $t_{y}$ is equivalent to a tax on all commodities at the same rate; any set of $\left(t_{s}, t_{g}, t_{x}\right)$ can be scaled up or down, with commensurate changes in $t_{y}$. Thus any one rate can be set to zero (see Fullerton, 1997).
} 
the elasticities of demand for these goods. But the way in which changes in size affect emissions is through the technological relationships that size has with emissions per mile and fuel efficiency. The functions $\operatorname{EPM}(s)$ and $M P G(s)$ are therefore major determinants of the second-best tax rates.

These first order conditions cannot be used to solve for the second-best uniform tax rates on size and gasoline. To find closed-form solutions we would have to specify the functional forms of $h(\alpha, \beta, y), \operatorname{EPM}(s), M P G(s)$ and the demands for size, miles, and the composite commodity. Still, these first order conditions can be used to shed some light on the nature of such taxes. First, note how this problem differs from the usual second-best optimal tax problem. Much of the public economics literature assumes that consumers demand leisure and other goods, that leisure cannot be taxed, and that the government must set other tax rates to minimize excess burden subject to a revenue requirement. The resulting second-best tax rates depend primarily on price elasticities: higher tax rates are placed on goods that are inelastically demanded or that are complements to leisure. ${ }^{25}$ In contrast, our problem does not involve any labor/leisure choice, or even a revenue requirement. Individual-specific lump-sum taxes are available. For this reason, the resulting second-best tax rates will not depend in the same way on behavioral responses to prices. The goal here, instead, is to tax something that approximates the consumer's emissions. In particular, if consumers with a high preference for miles (high $\alpha$ ) also happen to have a high preference for size (high $\beta$ ), then that correlation is likely to affect the second-best optimal $t_{g}$ and $t_{s}$. In addition, preferences for size determine emissions through the relationship size has with $M P G$ and $E P M$.

We therefore want to investigate the potential importance of these technological relationships and of the correlation between miles and size. In addition, first order conditions (23) do not provide clear guidance about how to set uniform tax rates in the face of heterogeneity. Closed-form solutions for the SBO tax rates are not available, but two alternatives come to mind. First, we can calculate the "expected value" or

\footnotetext{
${ }^{24}$ When an emissions tax achieves the FBSO, where $\lambda=\lambda^{*}$, then (23a) says that the cost to the taxpayer of an increase in $t_{s}$ is the amount of $s$ purchased, and that this marginal cost should be equal to the marginal benefits in terms of reduced emissions.
} 
weighted average of the first-best individual-specific tax rates in equations (20) and (21). These average rates might then be applied uniformly to all individuals. These rates are not the same as the SBO rates from (23), but at least they incorporate information about the distribution $h(\alpha, \beta, y)$ of heterogeneous individuals. Second, policymakers might simply ignore heterogeneity, and just use the economy-wide means for miles and size as if all individuals were the same. A comparison of these two alternatives will reveal the direction of the bias from ignoring heterogeneity.

The average of all different gas tax rates in (20) is:

$\bar{t}_{g}=\frac{\iint_{\beta} \int_{y} n \mu E P M\left(s_{i}\right) M P G\left(s_{i}\right) h(\alpha, \beta, y) \partial \alpha \partial \beta \partial y}{\iint_{\beta} \int_{y} h(\alpha, \beta, y) \partial \alpha \partial \beta \partial y}=\iint_{\alpha} \int_{y} \mu E P M\left(s_{i}\right) M P G\left(s_{i}\right) h(\alpha, \beta, y) \partial \alpha \partial \beta \partial y$

We ask how this concept differs from the simple calculation of the gas tax rate for the person with average choices:

$$
t_{g}(\bar{s})=n \mu E P M(\bar{s}) M P G(\bar{s})
$$

Specifically, we want to identify the circumstances under which the average of the gas $\operatorname{tax}$ in (25) is greater than the gas tax rate for the person with average choices in (26). We can thus discover the conditions under which uniform taxes based on average choices would likely fall short of attaining the second-best emissions reduction.

Note that households with bigger cars driving proportionally more miles than small-car owners would pay a proportionally higher gas tax even with a uniform gas tax rate, because they would use more gas to drive the extra miles. Whether (25) exceeds (26) depends on the characteristics of $\operatorname{EPM}(s)$ and $M P G(s)$ and particularly on the convexity of each function. Convexity of $\operatorname{EPM}(s)$, for example, would mean that increases in size increase emissions per mile at an increasing rate. This would raise the

\footnotetext{
${ }^{25}$ For comprehensive treatments of optimal taxation, see Auerbach (1985) or Stern (1987).
} 
weighted average using $E P M\left(s_{i}\right)$ in (25) relative to the tax rate using average size in (26). Convexity in $M P G(s)$ also raises (25) relative to (26). So, if either function is sufficiently convex (or if both are convex), then the use of average size to calculate the gas tax rate would understate the second-best uniform tax rate. Conversely, if either $\operatorname{EPM}(s)$ or $M P G(s)$ is sufficiently concave, then using the average value of size to calculate the gas tax rate would overstate the second-best uniform tax rate.

To determine the likely magnitude of (25) relative to (26), we need estimates of the possible nonlinear effect of engine size on fuel efficiency and emissions. While it is widely known that fuel efficiency decreases with engine size, a literature search locates no statistical estimates of the nonlinear nature of this relationship. Nor could we find any estimates of the effect of size on emissions per mile. ${ }^{26}$ For these reasons, we use the CARB data to estimate $E P M$ and $M P G$ as polynomial functions of engine size. These regressions omit other explanatory variables in order to capture the full effect of size, the only taxed characteristic. These very preliminary results suggest that $E P M$ is increasing over most of the range of size and convex, while $M P G$ is decreasing and also convex in size. ${ }^{27}$ Thus the use of average car size would likely understate the second-best optimal gas tax.

Now consider the individual-specific size tax rate in (21). We want to reveal the circumstances under which the average of the size tax rate,

$$
\bar{t}_{s}=\iint_{\alpha} \int_{\beta} \mu E P M_{s i} m_{i} h(\alpha, \beta, y) \partial \alpha \partial \beta \partial y+\iint_{\alpha} \int_{y} \frac{\mu E P M\left(s_{i}\right) M P G_{s i} m_{i}}{M P G\left(s_{i}\right)} h(\alpha, \beta, y) \partial \alpha \partial \beta \partial y
$$

is larger than the size tax for the person with the average choices,

\footnotetext{
${ }^{26}$ Dunleep (1992) provides only rough estimates of the effect of size on $M P G$. Kabn (1996b) examines the effect of size on emissions in parts per million rather than on emissions per mile.

${ }^{27}$ Typical results for regressions of $E P M$ on size are shown in footnote (22). The following regression indicates that $M P G$ is decreasing and also convex in engine size measured by CID (standard errors in parentheses):

$$
M P G=\underset{(.88)}{35.41-.106 \mathrm{CID}}+\underset{(.0085)}{3.00012 \mathrm{CID}^{2}} \quad \mathrm{R}^{2}=.72, \mathrm{n}=342
$$

EPA data on MPG yield similar results.
} 


$$
t_{s}(\bar{s}, \bar{m})=n \mu E P M_{\bar{s}} \bar{m}+\frac{n \mu E P M(\bar{s}) M P G_{\bar{s}} \bar{m}}{M P G(\bar{s})}
$$

If the size tax is positive, then emissions per mile increase proportionately more with size than fuel efficiency deteriorates, and the first terms in (27) and (28) dominate the second terms. In this case, whether the average size tax rate (27) exceeds the size tax rate using average miles and size (in 28) depends only on whether the first term in (27) exceeds the first term in (28). Note that in the first term of each equation, $E P M_{s}$ is multiplied by $m$. If size and miles are positively correlated, because $\alpha$ and $\beta$ are positively correlated, then this term is superadditive in miles and size. In this case, even if $\operatorname{EPM}(s)$ is linear, (27) exceeds (28). The use of the average person's size tax is likely to understate the second-best size tax, if those who own larger cars drive proportionately more miles than those with smaller cars. Moreover, if $E P M$ is a convex function of size, then the optimal size tax increases even more quickly with miles and size. Conversely, if miles and size are negatively correlated and EPM is linear or concave in size, then (27) would be less than (28).

We use the 1994 Residential Transportation Energy Consumption Survey (RTECS) to find preliminary evidence on the correlation of size and miles, and find a very small but statistically significant negative correlation. ${ }^{28}$ However, since preliminary estimates show $\operatorname{EPM}(s)$ to be convex, we cannot determine whether the size tax based on average size would likely overstate or understate the second-best uniform size tax.

Do uniform tax rates calculated using mean miles and size and (20) and (21) approximate the second-best tax rates? We have shown that the answer depends on the technological relationships $E P M(s)$ and $M P G(s)$, and the relationship between preferences for size and miles $h(\alpha, \beta, y)$. The average gas tax is likely to exceed the tax calculated using average size, since $E P M$ and $M P G$ are found to be convex in size. The average size tax may exceed the size tax calculated using average size and miles,

\footnotetext{
${ }^{28}$ We use the RTECS because other sources lack data on annual miles or engine size. CARB data does not list annual mileage, while the Nationwide Personal Transportation Survey (NPTS) has annual miles but not engine size. The 1994 Consumer Expenditure Survey has multiple odometer readings that enable mileage to be calculated, and it has the number of cylinders, but not CID. Using vehicles in the RTECS,
} 
but only if size and miles are positively correlated and/or $E P M$ is sufficiently convex in size. In contrast, if tastes for size and miles are independently distributed and emissions per mile and miles per gallon are linear functions of size, then average tax rates equal the tax rates calculated using mean miles and size.

It appears unlikely that the second-best uniform tax rates would be closely approximated by the rates based on the means. In order to maximize social welfare, we need a comprehensive empirical investigation of the technological relationships $\operatorname{EPM}(s)$ and $M P G(s)$, the distribution $h(\alpha, \beta, y)$, and behavioral parameters.

\section{Conclusions}

In a simple model, we duplicate the outcome from a tax on emissions by instead taxing gasoline and engine size, and by subsidizing PCE. The gas tax induces households to drive fewer miles and to buy more fuel-efficient cars. In addition, since the rate of tax depends on the cleanliness of the gasoline, the optimal gas tax also encourages households to buy cleaner fuel. The tax on size induces households to buy cars with smaller engines, while a subsidy to $P C E$ encourages purchase and repair of emissions-reducing equipment. Of course, vehicle age is also an important determinant of emissions, because emissions standards have become increasingly stringent over time, because emissions-control equipment deteriorates over time, and because new technologies and lighter materials have become available. Thus policies that accelerate vehicle retirement might also reduce emissions in a cost-effective way. The theory in this paper could be extended to incorporate such policies. ${ }^{29}$

Current policies for the control of car pollution already involve many government mandates, in addition to some economic incentives. We do not include any explicit vehicle-emissions standards in our model, but we recognize that existing standards affect the current relationships between vehicle size, vehicle age, and

${ }^{29}$ Alberini, et al., (1995, 1996) derive a theoretical model of owners' car tenure and scrappage decisions, and they analyze the results from an experimental vehicle retirement program in Delaware. Innes (1996) and Fullerton and West (1999) also incorporate vintage choice into their models. 
emissions per mile. Thus incentives that affect the choice of vehicle rely for their effectiveness on the existence of those standards.

While the model of homogeneous consumers is useful to clarify the role of each alternative policy in attaining the social optimum, it cannot tell us how variation in tastes for miles and size might affect optimal tax or subsidy rates. To explore this issue, we build a model of consumers that differ by tastes for miles and engine size. The firstbest alternative policies are household-specific taxes on gasoline and size. For the firstbest gas tax to be feasible, the attributes of each vehicle would have to be identifiable at the pump.

Because such implementation would likely be expensive, we characterize second-best uniform tax rates. A simple alternative is based on the erroneous assumption that consumers are identical and so all drive the mean number of miles in the mean sized car. We reach two main conclusions. First, if the addition of a unit of size increases emissions per mile at an increasing rate, or if it decreases fuel efficiency at a decreasing rate, then a second-best uniform gas tax rate would exceed that simple calculation (using mean size and miles). Second, because we identify consumer preferences using two parameters, one for miles and one for size, we find that a higher positive correlation of these taste parameters increases the second-best uniform tax on size.

If tastes for miles and size are positively correlated, and $E P M$ and $M P G$ are convex in size, then second-best uniform tax rates are likely to be larger than tax rates calculated by ignoring heterogeneity (using the means of size and miles). Only if tastes are independently distributed and both $E P M$ and $M P G$ are linear would the tax rates evaluated at the means be optimal. Thus an investigation of the economic incentives for the control of car pollution requires empirical exploration of the technological relationships between vehicle attributes and emissions per mile, and of the distribution of preferences for miles and size. 


\section{References}

Alberini, Anna, Winston Harrington and Virginia McConnell. "Determinants of Participation in Accelerated Vehicle-retirement Programs." The Rand Journal of Economics 26 (Spring 1995): 93-112.

Alberini, Anna, Winston Harrington and Virginia McConnell. "Estimating an Emissions Supply Function from Accelerated Vehicle Retirement Programs." The Review of Economics and Statistics 78 (May 1996): 251-263.

Auerbach, Alan J. "The Theory of Excess Burden and Optimal Taxation," in Martin Feldstein and Alan Auerbach, eds., Handbook of Public Economics, Volume 1. (Amsterdam: North Holland, 1985): 61-125.

Baumol, William J. and Wallace E. Oates. Theory of Environmental Policy. Second edition. (New York: Cambridge University Press, 1988).

Bohm, Peter and Clifford S. Russell. "Comparative Analysis of Alternative Policy Instruments," in Allen V. Kneese and James L. Sweeney, eds., Handbook of Natural Resource and Energy Economics, Volume 1. (Amsterdam: North Holland, 1985): 395-460.

Bradsher, Keith. "Favors Benefit Light Trucks, But May Be Harmful." The Austin American-Statesman. (December 7, 1997): A25, A42, A43.

Burmich, Pam. The Air Pollution-Transportation Linkage. (Sacramento, CA: State of California Air Resources Board, Office of Strategic Planning, 1989).

California Air Resources Board (CARB). Test Report of the Light-Duty Vehicle Surveillance Program, Series 13 (LDVSP13) Project. (September 3, 1997).

Dunleep, K.G. NEMS Transportation Sector Model. (Arlington, VA: Energy and Environmental Analysis, 1992).

Eskeland, Gunnar. "A Presumptive Pigovian Tax: Complementing Regulation to Mimic an Emissions Fee." The World Bank Economic Review 8.3 (September 1994): 373-394.

Eskeland, Gunnar and Shantayanan Devarajan. Taxing Bads by Taxing Goods: Pollution Control with Presumptive Charges. (Washington, DC: The World Bank, 1996).

Faiz, Asif, Christopher S. Weaver and Michael P. Walsh. Air Pollution From Motor Vehicles. (Washington, DC: The World Bank, 1996). 
Fullerton, Don. "Environmental Levies and Distortionary Taxation: Comment." The American Economic Review 87 (March 1997): 245-251.

Fullerton, Don and Ann Wolverton. "The Case for a Two-Part Instrument: Presumptive Tax and Environmental Subsidy," forthcoming in Paul R. Portney and Robert M. Schwab, eds., Environmental Economics and Public Policy: Essays in Honor of Wallace E. Oates. (Cheltenham, UK: Edward Elgar Publishing Ltd., 1999).

Fullerton, Don and Sarah West. "Tax and Subsidy Combinations for the Control of Car Pollution." Working paper prepared for the Public Policy Institute of California (March, 1999).

Goldberg, Pinelopi K. "The Effects of Corporate Average Fuel Efficiency Standards in the US." The Journal of Industrial Economics 46 (March 1998): 1-33.

Hall, Jane V., Arthur M. Winer, Michael T. Kleinman, Frederick W. Lurmann, Victor Brajer and Steven D. Colome. "Valuing the Health Benefits of Clean Air." Science 255 (February 14, 1992): 812-817.

Harrington, Winston. "Fuel Economy and Motor Vehicle Emissions." Journal of Environmental Economics and Management 33 (July 1997): 240-252.

Harrington, Winston, Margaret Walls and Virginia McConnell. "Shifting Gears: New Directions for Cars and Clean Air." Discussion Paper 94-26-REV. (Washington, DC: Resources for the Future, 1994).

Harrington, Winston, Virginia McConnell and Anna Alberini. "Economic Incentive Policies under Uncertainty: The Case of Vehicle Emission Fees," in Roberto Roson and Kenneth A. Small, eds., Environment and Transport in Economic Modelling. (Dordrect, The Netherlands: Kluwer Academic Publishers, 1998).

Innes, Robert. "Regulating Automobile Pollution Under Certainty, Competition, and Imperfect Information." Journal of Environmental Economics and Management 31 (September 1996): 219-239.

Kahn, Matthew E. "New Estimates of the Benefits of Vehicle Emissions Regulation." Economics Letters 51 (June 1996a): 363-369.

Kahn, Matthew E. "New Evidence on Trends in Vehicle Emissions." Rand Journal of Economics 27 (Spring 1996b): 183-196.

Kazimi, Camilla. "Evaluating the Environmental Impact of Alternative-Fuel Vehicles." Journal of Environmental Economics and Management 33 (June 1997): 163185. 
Kling, Catherine L. "Emissions Trading versus Rigid Regulations in the Control of Vehicle Emissions." Land Economics 70 (May 1994): 174-188.

Kohn, Robert E. "An Additive Tax and Subsidy for Controlling Automobile Pollution." Applied Economics Letters 3 (July 1996): 459-462.

Krupnick, Alan J. and Paul R. Portney. "Controlling Urban Air Pollution: A Benefit Cost Assessment." Science 252 (April 26, 1991): 522-528.

Krupnick, Alan J. and Margaret A. Walls. "The Cost-effectiveness of Methanol for Reducing Motor Vehicle Emissions and Urban Ozone." Journal of Policy Analysis and Management 11 (Summer 1992): 373-396.

Organization for Economic Co-operation and Development (OECD). Motor Vehicle Pollution: Reduction Strategies Beyond 2010. (Paris: OECD, 1995).

Pigou, Arthur C. The Economics of Welfare. Fourth edition. (London: MacMillan and Co., 1932).

Sevigny, Maureen. Taxing Automobile Emissions for Pollution Control. (Cheltenham, UK: Edward Elgar Publishing Ltd., 1998).

Sierra Research. "Analysis of the Effectiveness and Cost-Effectiveness of Remote Sensing Devices." Report SR94-05-05, prepared for the U.S. Environmental Protection Agency. (Sacramento, CA: Sierra Research, 1994).

Small, Kenneth A. and Camilla Kazimi. "On the Costs of Air Pollution from Motor Vehicles." Journal of Transport Economics and Policy 29 (January 1995): 7-32.

Stern, Nicholas H. "The Theory of Optimal Commodity and Income Taxation: An Introduction," in David M. Newbery and Nicholas H. Stern, eds., The Theory of Taxation in Developing Countries. (Oxford: Oxford University Press, 1987): 2259.

Train, Kenneth E., William B. Davis and Mark D. Levine. "Fees and Rebates on New Vehicles: Impacts on Fuel Efficiency, Carbon Dioxide Emissions, and Consumer Surplus." Transportation Research (Logistics and Transportation Review) 33 (1997): 1-13. 